\title{
Ovipositor sources for queen-rearing of honey bee (Apis mellifera) revealed inheritable maternal effect on reared queen
}

\author{
Longtao Yu \\ Jiangxi Agricultural University \\ Xinxin Shi \\ Jiangxi Agricultural University \\ Xujiang He \\ Jiangxi Agricultural University \\ Weiyu Yan \\ Jiangxi Agricultural University \\ Xiaobo Wu ( $\square$ wuxiaobo21@163.com ) \\ Honeybee Research Institute, Jiangxi Agricultural University
}

\section{Research}

Keywords: Honey bee, Queen-rearing, Ovipositor sources, Queen quality, Maternal effect, Offspring

Posted Date: October 13th, 2021

DOl: https://doi.org/10.21203/rs.3.rs-957526/v1

License: (a) (i) This work is licensed under a Creative Commons Attribution 4.0 International License. Read Full License 


\section{Abstract}

Queen is arguably the most important member of a honey bee colony, and queen quality is crucial for honey bee colony growth and development. In this study, queens were reared with eggs laid in queen cells $(Q E)$, eggs laid in worker cells (WE) and 2-day old larvae in worker cells (L). Those physiological indexes (the weight, thorax size and number of ovarioles) of newly reared queens in each group were measured. Moreover, the reproductive potential of the newly reared queens and foraging ability of worker bees laid by the newly reared queens in each group were further explored. In addition, we also examined whether maternal effects would be transmitted to the offspring queens in honey bee. We found that the weight, number of ovarioles and thorax weight of newly emerged queens in QE were significantly higher than those in WE and L, suggesting the reproductive potential was stronger in QE group than WE and $L$ group. Furthermore, offspring worker bees and queens of QE queens had higher weight at emergence than those from the other two groups. This study proved profound honey bee maternal effects on queen quality, which can be transmitted to their offspring. Our results of the present study were important for improving queen quality and promoting the development of beekeeping and agriculture.

\section{Introduction}

Honey bee is a society insect that is extremely close to human, which provides abundant bee-products and pollinates plants to balance the ecological nature. The economic value of bee pollination was estimated to be more than 14.6 billion annually in the United States (Elliud et al.,2014). However, the population of bee colonies has a dramatic decline in the United States, France, Germany, Austria, Switzerland and other counties (Stankus.,2008; Ratnieks et al.,2010). The mechanism for the occurrence of CCD in honey bee is still unclear, but poor queen quality could be a major contributor to the mass death of honey bee (vanEngelsdorp et al.,2011; Lee et al.,2019). High-quality honey bee queen is the key to bee colony development and high-production of bee products. As a result, rearing high-quality honey bee queens attracts many beekeepers and researchers.

Honey bee colony consists of thousands of worker bees, many drones and a queen, and the queen is the only individual with full reproductive capacity in the colony which is dedicated to lay eggs. Indeed, there is only one queen in the honey bee colony, but worker bees will build queen cells with great enthusiasm and let the honey bee queen to lies egg in the queen cell in colony flourishing season, which develops to a new queen and swarm for a more colony. In addition, worker bees will reform worker cell with egg or larva into queen cell and the egg or larva will develop to a new queen when the colony loss the old queen bee unexpectedly. Studies revealed that the quality of queens reared by young larvae were less favored than queens reared by eggs, and the quality of queens decreased with the reared larvae age (Woyle.,1971; Rangel.,2012; Yi et al.,2020). Also, the growth of colonies with queens reared with older larvae is slower than that reared with younger larvae (Rangel.,2012). In other words, the younger the age of larvae, the better the quality of queens were reared. However, the differences of queens reared with eggs in queen cells, worker cells and larvae for reproductivity of these queens and the quality of their offspring is unclear. 
Hence, the research was based on a new method for producing royal jelly without grafting larvae (Pan et al.,2013; Wu et al., 2015; Hu et al.,2017), queens reared with eggs laid in queen cells, eggs laid in worker cells and larvae, in worker cells and we compared the quality and reproductive potential (Amiri et al.,2017) of the queens reared with the three ova sources. After that, the quality of their offspring (queens and worker bees) laid by the reared queens was further explored. The results of this study are devoted to rear high-quality queens, which is important for the promotion of beekeeping.

\section{Materials And Methods}

\subsection{Insects and queen rearing}

Honey bee (Apis mellifera) colonies were kept at the Honeybee Research Institute, Jiangxi Agricultural University, Nanchang, China $\left(28.46^{\circ} \mathrm{N}, 115.49^{\circ} \mathrm{E}\right)$, according to standard beekeeping techniques. Each colony had nine frames with approximately 30,000 workers and a naturally mated queen.

In this study, we compared the differences of reared queens with three ovipositor sources: eggs laid in queen cells (QE), eggs laid in worker cells (WE) and 2-day old worker larvae (L). To produce these queens, a naturally mated laying queen was controlled on plastic queen cells for laying eggs for $12 \mathrm{~h}$, and the queen cells with eggs were transferred to colony for queen rearing (Wu et al., 2015). After that, the queen was controlled for $12 \mathrm{~h}$ on a frame of worker cells to lay (Pan et al. 2013), a total of 192 eggs in worker cells and 90 eggs were transferred to queen cells on the 2 nd day for queen rearing with the new method (Wei et al.,2019). The rest of eggs in worker cells hatched to larvae, which were transferred to queen cells on the 5th day (from laid eggs, 2-day old larvae). All the queen cells with egg and larvae were kept in the same colony, and newly emerged queens were harvested immediately for weight. Some of emerged queens were kept in queen-less colonies for the number of ovarioles, the scoring ovariole number method was the same as previous report (Yi et al.,2020), and 4 newly emerged queens in each group were kept in mating colonies and mated naturally. The rest of emerged queens were snap-frozen in liquid $\mathrm{N}_{2}$ for queen thorax size measurement (queen thorax length, width, weight). All experiments were repeated three times and conducted in three honey bee colonies.

\subsection{Reproductive quality of queens}

After newly emerged queens mated and lied eggs, we weigh the same weight (1000 g) of worker bees to form new colonies, then these queens were put into the new colonies separately. Meanwhile, we put foundations into beehives for comb building, and queens lied eggs on the combs. Thereafter, we counted the number of eggs laid by queens of the three group from 8:00 to 14:00 of each day within 6 days. Additionally, we measured the number of capped cells of the three groups every 12 days from the queens started laying eggs, and the number of capped cells were measured four times in a row. These studies were conducted in nine colonies contained three biological repetitions.

\subsection{Quality of newly emerged worker bees and the flight and collection capabilities of forager bees}


The size of eggs laid by those new reared queens within $2 \mathrm{~h}$ from each group of queens were explored. Meanwhile, capped brood in the colonies with the new reared queens was removed from QE, WE and $\mathrm{L}$ colony and transferred into an incubator at $34{ }^{\circ} \mathrm{C}, 70 \pm 5 \%$ relative humidity for emergence. Newly emerged worker bees were weighed and these worker bees in each group were marked with different colors, then were poured into the same colony. On the 26th day (from worker bees emerged), we captured forager bees with different color markers at the beehive entrance, and we stripped pollen cluster from these forager bees and weighed the collected pollen. Additionally, the wings size (length and width) of these forager bees from each group were measured. Furthermore, reared queens were controlled on an empty comb for $2 \mathrm{~h}$ to lay eggs. These eggs hatched into larvae (1-day old), and were transferred to artificial queen cells for royal jelly harvesting in their native colonies. Two days later, we harvested royal jelly in each group and measured the weight of the royal jelly.

\subsection{Quality of offspring queens}

To rear new offspring queens, we controlled reared queens on an empty comb for $2 \mathrm{~h}$, the eggs laid by queens in each group were kept in their native colonies. Four days later, the larvae were transferred to artificial queen cells, and were kept in the same colony. After offspring queens emerged, we measured the weight and thorax size of newly emerged queens immediately. All samples were stored in a $-80^{\circ} \mathrm{C}$ freezer.

\subsection{Statistical analysis}

Statistical analyses were performed in SPSS Statistics version 26, and the abnormal values (values over mean \pm 3 times standard error were abnormal, $>99 \%$ confidence interval) were removed. All differences among the three groups were determined by one-way ANOVA, and Fisher's LSD tests was used to determine any differences among different groups.

\section{Results}

\subsection{Physical indexes of virgin queens}

There was significant difference in weight of reared queens from three ova sources (Fig. 1a, ANOVA: $F_{2,36}$ $=7.483, \mathrm{DF}=2, P<0.05)$ and the number of ovarioles for newly emerged virgin queens (Fig. 1b, ANOVA: $\left.F_{2,18}=21.951, \mathrm{DF}=2, P<0.001\right)$. Queen weight and the number of ovarioles from QE were significantly higher than WE and L, and those in WE were significantly higher than L. Moreover, the thorax width of queens in QE and WE was significantly higher than those in $L$ (Fig. 1c, ANOVA: $F_{2,25}=19.409, D F=2, P<$ 0.001 ), while no significant was found in the thorax length among the three groups (Fig. 1C, ANOVA: $F_{2,25}$ $=1.064, \mathrm{DF}=2, \mathrm{P}=0.360$ ); The thorax weight of queens in QE was significantly higher than those in WE and $L$, and WE was significantly higher than $L$ (Fig. $1 d, F_{2,10}=27.728, D F=2, P<0.001$ ).

\subsection{Reproductive quality of reared queens}


The number of eggs laid by reared queens in QE was significantly higher than those of $L$ group, and there was no significant difference between QE and WE, WE and L (Figure 2a, ANOVA: $F_{2,15}=2.866, \mathrm{DF}=2, P=$ 0.088). Furthermore, we explored honey bee colony growth potential of queens among the three groups by counting the number of capped brood cells at a period of 12 days. The number of capped brood cells was consistent with the queen's ability to lay eggs, as shown in Fig. $2 \mathrm{~b}$, the number of capped brood cells of QE colony was significantly higher than $L$, while there was no significant difference between $Q E$ and WE, WE and $L\left(A N O V A: F_{2,9}=5.612, D F=2, P<0.05\right.$ ).

\subsection{Quality of newly emerged worker bees and the flight and collection capabilities of forager bees}

The length of eggs laid by QE queen were significantly higher than WE and $L$ (Fig. 3b, ANOVA: $F_{2,16}=$ 30.441, $\mathrm{DF}=2, \mathrm{P}<0.001$ ). However, there was no significant difference in the weight of eggs (Fig. $3 a$, ANOVA: $F_{2,45}=0.839, D F=2, P=0.439$ ) and width of eggs (Fig. $3 b$, ANOVA: $F_{2,15}=1.001, D F=2, P=$ 0.391 ) among the three groups. Additionally, Worker bees of QE were significantly heavier than WE and $L$ at emergence, while no significant difference was found between WE and L (Fig. 3c, ANOVA: $F_{2,74}=$ $11.217, D F=2, P<0.001)$. Furthermore, the weight of pollen in legs of forager bees in $Q E$ and WE were significantly higher than $L$ ( $F i g .3 d$, ANOVA: $F_{2,31}=4.952$, DF $=2, P<0.05$ ), while no statistical difference was found between QE and WE. The wings size of forager bees from each group as shown in Fig. 3e, wings length in QE group was significantly higher than WE, but there was no significant difference between QE and L, WE and L (ANOVA: $F_{2,29}=4.294, D F=2, P<0.05$ ). Also, wings width of QE was significantly higher than WE and $L$, but there was no significant difference between WE and L (ANOVA: $\left.F_{2,28}=10.360, D F=2, P<0.001\right)$. In addition, the production of royal jelly in QE group was higher than WE and $L$, but no significant difference were found between WE and $L$ (Fig. 3f, ANOVA: F2,25 =9.439, DF = 2, $P<0.05)$.

\subsection{Quality of the offspring queens}

Weight of newly emerged offspring queens of QE were significantly higher than WE and $L$, while no significant difference was found between WE and L (Fig. 4a, ANOVA: $F_{2,14}=3.998, D F=2, P<0.05$ ). Moreover, the thorax weight (Fig. 4b, ANOVA: $F_{2,19}=34.726$, DF $=2, P<0.001$ ), width (Fig. 4c, ANOVA: $F_{2,27}=6.704, D F=2, P<0.005$ ), length (Fig. 4c, ANOVA: $F_{2,27}=9.225, D F=2, P<0.001$ ) of newly emerged offspring queens of QE were significantly higher than WE and L, but there was no significant difference between WE and $\mathrm{L}$.

\section{Discussion}

Many factors, such as larval diet, developmental space and rearing management result huge differentiation in queen development (Wei et al.,2019; Yi et al.,2020; He et al.,2021). Researchers explored methods in high-quality queen rearing (Woyle.,1971; Gabka et al.,2011; Rangel.,2012; Wei et al.,2019). 
Previous study found that the size of eggs laid in queen cells was larger than in worker cells, and the weight of newly emerged and the number of ovarioles of queens rearing with eggs in queen cells was larger than in worker cells and 2-day old larvae (Wei et al.,2019). Furthermore, the larger the eggs used, the larger the reared queen. Hence, the quality of queens in QE was better than WE. In addition, nurse bees feed larvae in worker cells with less worker jelly and provide larvae in queen cells with abundant royal jelly. The difference in food nutrition provides to QE and L larvae developing, which resulting huge differences in the quality of queens (Wang et al.,2016).

The growth, productivity, and survival of a colony depends in large part on the health and reproductive capacity of its queen (Tarpy et al.,2013; Rangel et al.,2012; Nelson et al.,1983;). The quantitative reproductive potential of a queen represents her "quality" (Amiri et al.,2017). Moreover, beekeepers prefer larger size with higher weight queens in commercial queen-rearing. Many pieces of evidences confirmed that the newly born weight, thorax size was strongly correlated with queen ovariole number which influences queen fecundity and quality (Nelson et al.,1983; Dodologlu et al.,2003; Amiri et al.,2017; Wei et al.,2019; He et al.,2021).

In fact, these results from the present study are consistent with our previous study (Wei et al., 2019) where QE showed significantly higher weight, ovariole number and thorax size than both WE and L. Our results agreed with the previous results (Wei et al., 2019; He et al.,2021), revealing that queens reared from eggs lied in queen cells was a practicable way for high-quality queens.

The production of honey and bee bread in colonies is extremely related to the collection capacity of forager bees. Moreover, the collection capacity of forager bees is strongly related to the area of wings which reflects in flight capacity (Zeng.,1992). In our study, the collected pollen cluster in legs of QE forager bees was much heavier than WE and L. Moreover, the wings length and width of QE forager bees were significantly higher than WE and $L$, suggesting that colonies with queens were reared from eggs in queen cells were more productive (Zeng.,1992; Blanken et al.,2015).

It is supposed that honey bee maternal effects had profound impacts on offspring phenotype (Wolf et al.,2009; Wei et al., 2019). However, it is unclear whether the quality difference in queens' development caused by maternal effects can be transmitted to their offspring and eugenics exists in honey bee colony. Therefore, we further explored the quality difference of worker and queen offspring among the three groups. We found that eggs laid by reared queens of QE were much bigger, and the quality of offspring worker bees and queens of QE were much better. Results of the present study showed that maternal effect had profound influences on queen development, and these influences will carry over their offspring, causing huge differences in the quality of their offspring.

Nevertheless, our results indicate difference in queen quality caused by maternal effects will accumulative in their later generations, we will compare the quality differences in the queen offspring from queens of QE group laid eggs in queen cells, grafted eggs laid by queens of WE group and grafted larvae developed from eggs laid by queens of $L$ group in the following study. In a word, rearing queens from eggs laid in queen cells is a practicable method for high-quality queens, which is important for 
promoting the development of beekeeping and agriculture. We also need to further explore the optimal conditions for queens laying eggs in queen cells to expand the scale of commercial queen-rearing from eggs lied in queen cells and gradually apply it to beekeeping practice.

\section{Conclusion}

Maternal effects play a crucial role in development of larvae for queen-rearing, causing profound influences on queen reproductive and growth of colony. The influences will extend to next gene rations of queens, as well as worker bees, resulting huge differences on quality of offspring queens and flight and collection capabilities of worker bees.

\section{Declarations}

\section{Acknowledgements}

We are grateful to Dr. Huang Q at the Jiangxi Agriculture University for his valuable comments and great help with the work.

\section{Author contribution statement}

In this work, $X$ Wu conceived this research and designed the experiments. $L$ Yu carried out the laboratory work and wrote the manuscript. X Shi assisted in the laboratory work, X He and W Yan contribute to the laboratory work. All authors read and approved the final manuscript.

\section{Funding}

This work was supported by grants from the National Natural Science Foundation of China (31960685) and the Academic and Technical Leader Projects of Major Disciplines in Jiangxi Province (20194BCJ22007).

\section{Availability of data and material}

Not applicable.

\section{Ethics approval and consent to participate}

Not applicable.

\section{Consent for publication}

Not applicable.

\section{Competing interests}

The authors declare that they have no competing interests. 


\section{References}

1. Amiri E, Strand MK, Rueppell O, Tarpy DR. Queen Quality and the Impact of Honey Bee Diseases on Queen Health: Potential for Interactions between Two Major Threats to Colony Health. Insects. 2017;8(2):48-66.

2. Blanken LJ, vanLangevelde $F$, vanDooremalen C,2015. Interaction between Varroa destructor and imidacloprid reduces flight capacity of honeybees. Proceedings of the Royal Society B: Biological Sciences, 282(1820): 20151738.

3. Dodologlu A, Gene F. Comparison of some features of queens reared from different honeybee (Apis mellifera L.) genotypes. J Appl Anim Res. 2003;24:105-9.

4. Elliud M, Harland P, Maryann F, James F, Baldwyn T, Tracey B, Joseph K, James N, Fiona M, Daniel M, James T, Christina G. 2014.Evaluation of the distribution and impacts of parasites, pathogens, and pesticides on honey bee (Apis mellifera) populations in East Africa. PLoS ONE, 9(4): e94459.

5. Gabka J, Ochnio M, Kaminski Z, Majewska BM. Effect of age of eggs used for rearing honey bee queens on the number of received queen cells. Journal of Apicultural Science. 2011;55(1):47-53.

6. He XJ, Wei H, Jiang WJ, Liu YB, Wu XB, Zeng ZJ. 2021. Honeybee (Apis mellifera) maternal effect causes alternation of DNA methylation regulating queen development. Sociobiology, 68(1): e5935.

7. Hu FL, Bíliková K, Casabianca H, Daniele G, Salmen EF, Feng M, Guan C, Han B, Krištof KT, Li JK, Li L, Li XA, Šimúth J, Wu LM, Wu YQ, Xue XF, Xue YB, Yamaguchi K, Zeng ZJ, Zheng HQ, Zhou JH. Standard methods for Apis mellifera royal jelly research. J Apic Res. 2019;58(2):1-68.

8. Lee KV, Goblirsch M, McDermott E, Tarpy DR, Spivak M. Is the Brood Pattern within a Honey Bee Colony a Reliable Indicator of Queen Quality? Insects. 2019;10(1):12-29.

9. Nelson DL, Gary NE. Honey productivity of honeybee colonies in relation to body weight, attractiveness and fecundity of the queen. J Apic Res. 1983;22:209-13.

10. Pan QZ, Wu XB, Guan C, Zeng Z. A new method of queen rearing without grafting larvae. AmBee J. 2013;153:1279-80.

11. Rangel JKJTD. The effects of honey bee (Apis mellifera L.) queen reproductive potential on colony growth. Insectes Soc. 2012;60:65-73.

12. Ratnieks FLW, Carreck NL. Clarity on honey bee collapse? Science. 2010;327(5962):152-3.

13. Stankus T. A Review and Bibliography of the Literature of Honey Bee Colony Collapse Disorder: A Poorly Understood Epidemic that Clearly Threatens the Successful Pollination of Billions of Dollars of Crops in America. Journal of Agricultural Food Information. 2008;9(2):115-43.

14. Tarpy DR. 2003. Genetic diversity within honeybee colonies prevents severe infections and promotes colony growth. Proc. R. Soc. B Sci, 270: 99-103.

15. Tarpy DR, vanEngelsdorp D, Pettis JS. Genetic diversity affects colony survivorship in commercial honey bee colonies. Naturwissenschaften. 2013;100(8):723-8.

16. vanEngelsdorp D, Meixner MD. 2010. A historical review of managed honey bee populations in Europe and the United States and the factors that may affect them. Journal of Invertebrate 
Pathology, 103 (supp-s): S80-S95.

17. vanEngelsdorp D, Hayes J Jr, Underwood RM, Caron D, Pettis J. A survey of managed honey bee colony losses in the USA, fall 2009 to winter 2010. J Apic Res. 2011;50(1):1-10.

18. Wang Y, Ma LT, Zhang WX, Cui XP, Wang HF, Xu BH. Comparison of the nutrient composition of royal jelly and worker jelly of honey bees (Apis mellifera). Apidologie. 2016;47:48-56.

19. Wei H, He XJ, Liao CH, Wu XB, Jiang WJ, Zhang B, Zhou LB, Zhang LZ, Barron AB, Zeng ZJ. A Maternal Effect on Queen Production in Honeybees. Curr Biol. 2019;29(13):2208-13.

20. Wolf JB, Wade MJ. What are maternal effects (and what are they not)? Philos. Trans R Soc Lond B Biol Sci. 2009;364:1107-15.

21. Woyle J. Correlations between the age at which honeybee brood was grafted, characteristics of the resultant queens, and results of insemination. J Apic Res. 1971;10:45-55.

22. Wu XB, Zhang F, Guan C, Pan QZ, Zhou LB, Yan WY, Zeng ZJ. A new method of royal jelly harvesting without grafting larvae. Entomological News. 2015;124(4):277-81.

23. Yi Y, Liu YB, Barron AB, Zeng ZJ. Effects of commercial queen rearing methods on queen fecundity and genome methylation. Apidologie. 2020;52:282-91.

24. Zeng ZJ,1992. Analysis of the correlation between morphological indicators of worker bees and honey production. Apiculture of China, (3):12-23.

\section{Figures}





Figure 1

The weight (a), number of ovarioles (b), thorax width, thorax length (c) and thorax weight (d) of reared queens among the three groups. Bars show mean \pm SE (standard error). Different letters above bars mean significant differences between groups $(P<0.05$, one-way ANOVA test followed with Fisher's LSD test). The same for Figure. 2, Figure. 3 and Figure. 4. 

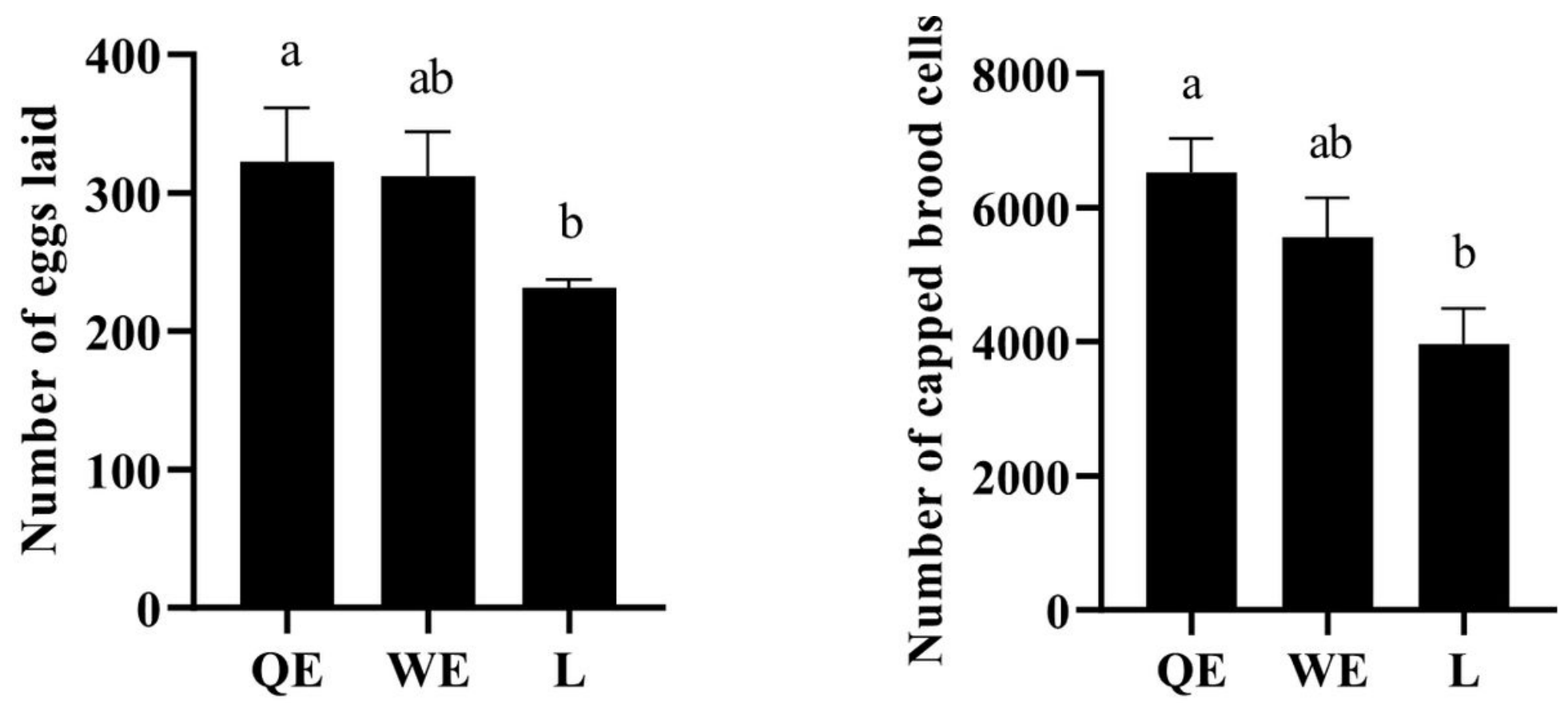

Figure 2

The number of eggs laid (a) by reared queens within $6 \mathrm{~h}$ and the number of capped brood cells (b) within 12 days in each group. 

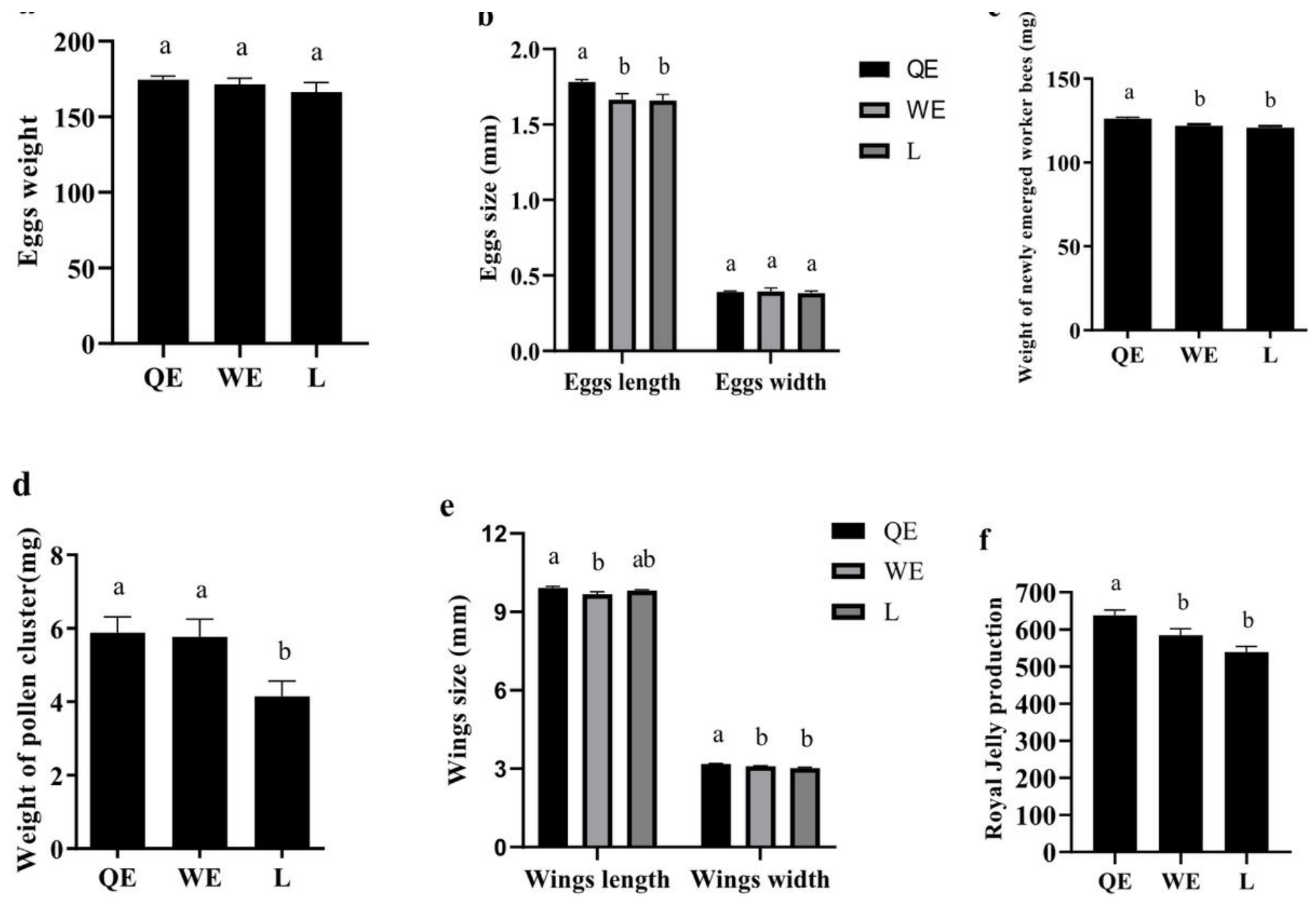

Figure 3

The weight of eggs (a), length, width of eggs (b) laid by reared queens, weight of newly emerged worker bees (c), weight of pollen in legs (d), wings size (e) of forager bees and royal jelly production (f) in each group.

Figure 4

Weight(a), thorax weight(b), thorax width and length(c) of newly emerged offspring queens in each group. 